\title{
AC 2007-1968: CIVIL AND MECHANICAL ENGINEERING STUDENTS LEARNING MECHANICS IN A MULTIDISCIPLINARY ENGINEERING FOUNDATION SPIRAL
}

\section{Jean Nocito-Gobel, University of New Haven}

Jean Nocito-Gobel, an Assistant Professor of Civil \& Environmental Engineering at the University of New Haven, received her Ph.D. from the University of Massachusetts, Amherst. She is currently serving as the Coordinator for the First Year Program. Her professional interests include modeling the transport and fate of contaminants in groundwater and surface water systems, as well as engineering education reform.

\section{Samuel Daniels, University of New Haven}

Samuel Bogan Daniels, Associate Professor of Mechanical Engineering, University of New Haven, received his Ph.D. in Mechanical Engineering from Boston University and has a P.E license in CT. He is currently the freshman advisor for Mechanical Engineering, ASME \& SAE Faculty Advisor, PLTW UNH Affiliate Professor, and has interests in solid modeling, electric vehicles and composites.

\section{Gregory Broderick, University of New Haven}

Gregory P. Broderick, a Professor of Civil \& Environmental Engineering at the University of New Haven, received his Ph.D. from the University of Texas at Austin. He is currently the Undergraduate Coordinator for the Civil Engineering Program, Freshman Advisor for Civil Engineering and PLTW/UNH Affiliate Professor. His professional interests include Soil and Slope Stabilization, Geosynthetics, Bioremediation, GIS and GPS as well as exploring new instruction pedagogies in engineering education.

\section{Michael Collura, University of New Haven}

Dr. Collura, Professor of Chemical Engineering at the University of New Haven, received his B.S. Chemical Engineering from Lafayette College and the M.S. and Ph.D. in Chemical Engineering from Lehigh University. His professional interests include the application of computers to process modeling and control, as well as reform of engineering education.

\section{Richard Stanley, University of New Haven}

Richard Stanley, a Professor of Mechanical Engineering at the University of New Haven, received his Ph.D. from Yale University. He is currently teaching a course in the First Year Program as well as a course that has prerequisites in both the first and second year of the program. His professional interests include computer-aided engineering and design. 


\section{Civil and Mechanical Engineering Students Learning Mechanics in a Multidisciplinary Engineering Foundation Spiral}

This paper describes how mechanical and civil engineering students are introduced to and develop an understanding of mechanics concepts through a sequence of integrated courses as part of a new curriculum taken during the freshman and sophomore years. The Multi-

Disciplinary Engineering Foundation Spiral is a four-semester sequence of engineering courses, matched closely with the development of students' mathematical sophistication and analytical capabilities and integrated with course work in the sciences. Students develop a conceptual understanding of engineering basics in this series of courses, which stress practical applications of these principles. Mechanics concepts are introduced in a pair of first year courses, EAS107P, Project-Based Introduction to Engineering and EAS112, Methods of Engineering Analysis. During the second year, students understanding of these concepts are further developed in three courses, two offered during the fall semester, EAS211, Introduction to Modeling of Engineering Systems and EAS213, Materials in Engineering Systems and one during the spring semester, EAS222, Fundamentals of Mechanics and Materials. In the third semester of discipline specific classes, ME300 Rigid Body Dynamics and CE312 Structural Analysis for mechanical and civil engineering respectively, students are evaluated compared to their peers who have either transferred in from other universities or taken a previous traditional sequence of mechanics courses.

The first course, EAS107P, introduces students to concepts related to structural systems and trusses, such as internal and external forces, reactions, compression and tension. This is done in the context of a team project in which students gain a qualitative understanding of these concepts using computer simulation models. In the second course EAS112, students use computer tools such as spreadsheets to solve problems including the analysis of trusses. Mechanics of materials are explored as students use spreadsheets to analyze tensile test properties. In the second year, resolution of forces is further developed in EAS211 as students use force balances to solve various statics problems. Students study the properties, behavior and application of materials in EAS213, including discussion of such concepts as torsion, compression, tension, fatigue, creep and fracture. This course focuses on the differences between materials and selection of materials for engineering applications. In EAS222, students develop an understanding of the basic principles and applications of engineering mechanics including the behavior of structures under various loads, bending and Mohr's circle.

This paper discusses how the mechanics topics are threaded through this sequence of courses and how mastery of these topics is being assessed at the disciplinary level in the junior year. Assessment of students' understanding of mechanics topics includes the following instruments: data drawn from quiz/exam grades and/or particular question(s) on exams/quizzes related to specific concepts; and faculty observations gathered using a survey tool. Our current data evaluates the first group of students to reach the junior level in the new curriculum that was implemented during the 2004-05 academic year. 


\section{Introduction}

Common to all civil and mechanical engineering programs are mechanics courses that are typically taught from a discipline specific perspective. Basic mechanics concepts are first introduced in physics courses often taken during the freshman year and then developed in sophomore level courses such as Statics, Strength of Materials and Dynamics. Transferring knowledge gained in these courses to discipline specific upper level courses is often a struggle for students.

During the 2004-05 academic year, faculty at the University of New Haven began the implementation of a new curriculum that stresses development of professional and technical skills during the first two years, while introducing basic engineering concepts. The Multi-

Disciplinary Engineering Foundation Spiral (MDEFS) is a four-semester sequence of engineering courses (EAS prefix), matched closely with the development of students' mathematical sophistication and analytical capabilities and integrated with course work in the sciences ${ }^{1}$. The purpose behind restructuring the curriculum was to take advantage of common professional and technical skill development that was repeated in the older, more traditional curriculum. The EAS sequence builds upon common problem solving courses that teach the core content areas with greater breadth and without the traditional narrow depth. As the students enter disciplinary courses in their junior and senior years, the traditional depth is still present, but it is hoped that the students have a broader view of engineering and are more able to work in the multidisciplinary environment of the engineer of 2020.

At the core of any problem in mechanics is a basic solutions approach that is common to thermofluid systems, electrical systems and other systems. The new curriculum emphasizes problem solving for a variety of systems through the use of conservation and accounting principles $^{2}$. This paper addresses how mechanics topics are threaded through the EAS sequence of courses, and how mastery of these topics is being assessed in the first semester junior level mechanics courses.

\section{Curriculum Changes}

The sequence of courses taken by students during their first two years in the traditional curriculum reflects a traditional approach to learning mechanics in civil (CE) and mechanical (ME) engineering programs. Students took their first physics course, PH150 Mechanics/Heat/Waves, in the traditional curriculum second semester freshman year in which they were introduced to basic particle kinematics and kinetics and force resolution. First semester sophomore year, students gained an understanding of the behavior of simple structures under various loadings, and investigated stresses and deformations as they relate to the design of simple mechanisms and structures in CE205 Statics and Strengths. This 4 credit course combined topics from both Statics and Strength of Materials traditionally taught as separate courses. The need to reduce overall credits in both the civil and mechanical engineering programs dictated the change to this combined course in the late 1990s. CE205 was taught by faculty in the civil engineering program and taken by both civil and mechanical engineering 
students. In addition to CE205, ME students were required to take ME200 Engineering Materials, a traditional materials science class, during their first semester sophomore year. All $\mathrm{CE}$ and ME students took a dynamics course, ME204, taught by the mechanical engineering faculty during the second semester sophomore year. For the most part, CE and ME students took common core mechanics courses during the sophomore year, taught from a discipline specific perspective.

However, like most engineering programs, mechanics courses offered first semester junior year are discipline specific. CE students took CE312 Structural Analysis in which students learn about the theory and application of structural analysis specifically applied to the analysis of trusses, beams and frames. The first semester junior year for ME students begins with the traditional core mechanical engineering course in Solid Mechanics (ME307), which includes elasticity and failure theories for combined stresses. Summarized in Figure 1 are the courses for both the traditional and new curriculum for CE and ME students.

\begin{tabular}{|c|c|c|c|c|}
\hline \multicolumn{5}{|c|}{ Traditional Curriculum } \\
\hline \multicolumn{4}{|c|}{ Civil Engineering Mechanics Sequence } & $\begin{array}{l}\text { First Junior Level } \\
\text { Mechanics Course }\end{array}$ \\
\hline Freshman & Freshman & Sophomore & Sophomore & Junior \\
\hline \multirow[t]{2}{*}{ First Semester } & Second Semester & First Semester & Second Semester & First Semester \\
\hline & $\begin{array}{c}\text { PH150 } \\
\text { Physics I (4 cr) }\end{array}$ & $\begin{array}{c}\text { CE205 Statics \& } \\
\text { Strength of Materials } \\
(4 \mathrm{cr})\end{array}$ & $\begin{array}{l}\text { ME204 Dynamics } \\
\text { (3 cr) }\end{array}$ & $\begin{array}{c}\text { CE312 } \\
\text { Structural Analysis (3 } \\
\text { cr) }\end{array}$ \\
\hline \multicolumn{4}{|c|}{ Mechanical Engineering Mechanics Sequence } & $\begin{array}{l}\text { First Junior Level } \\
\text { Mechanics Course }\end{array}$ \\
\hline Freshman & Freshman & Sophomore & Sophomore & Junior \\
\hline \multirow[t]{3}{*}{ First Semester } & Second Semester & First Semester & Second Semester & First Semester \\
\hline & \multirow{2}{*}{$\begin{array}{c}\text { PH150 } \\
\text { Physics I (4 cr) }\end{array}$} & $\begin{array}{c}\text { CE205 } \\
\text { Statics \& Strength of } \\
\text { Materials }(4 \mathrm{cr})\end{array}$ & \multirow{2}{*}{$\begin{array}{c}\text { ME204 Dynamics } \\
\text { (3 cr) }\end{array}$} & \multirow{2}{*}{$\begin{array}{l}\text { ME307 Solid } \\
\text { Mechanics }(3 \mathrm{cr})\end{array}$} \\
\hline & & $\begin{array}{l}\text { ME200 Engineering } \\
\text { Materials (3cr) }\end{array}$ & & \\
\hline \multicolumn{5}{|c|}{ New Curriculum (MDEFS) } \\
\hline \multicolumn{4}{|c|}{ Engineering Mechanics Sequence } & $\begin{array}{l}\text { First Junior Level } \\
\text { Mechanics Course }\end{array}$ \\
\hline Freshman & Freshman & Sophomore & Sophomore & Junior \\
\hline First Semester & Second Semester & First Semester & Second Semester & First Semester \\
\hline \multirow{3}{*}{$\begin{array}{l}\text { EAS107P Intro } \\
\text { to Eng.-Project- } \\
\text { based }(3 \mathrm{cr})\end{array}$} & \multirow{3}{*}{$\begin{array}{c}\text { EAS112 Methods of } \\
\text { Eng. Analysis } \\
(3 \mathrm{cr})\end{array}$} & $\begin{array}{l}\text { EAS211 Intro to } \\
\text { Modeling of Eng. } \\
\text { Sys. }(3 \mathrm{cr}) \\
\end{array}$ & \multirow{3}{*}{$\begin{array}{l}\text { EAS222 Mechanics } \\
\text { and Materials }(3 \mathrm{cr})\end{array}$} & $\begin{array}{c}\text { Civil: } \text { CE312 } \\
\text { Structural Analysis (3 } \\
\text { cr) }\end{array}$ \\
\hline & & $\begin{array}{l}\text { EAS213 Materials in } \\
\text { Eng. Sys. }(3 \mathrm{cr})\end{array}$ & & $\begin{array}{c}\text { Mechanical: } \text { ME300 } \\
\text { Rigid Body Dynamics } \\
\text { (3 cr) }\end{array}$ \\
\hline & & PH150 Physics I(4 cr) & & $\begin{array}{l}\text { ME308 Applied } \\
\text { Elasticity }(3 \mathrm{cr})\end{array}$ \\
\hline
\end{tabular}

Figure 1. Comparison of the Traditional \& New Courses with Mechanics Content 
In contrast to the traditional curriculum, the new curriculum features a number of additions to the coverage of mechanics topics in the first two years. The new curriculum is structured to retain the commonality of courses taken by CE and ME students in the sophomore year, however, not the discipline specific nature of these courses. All EAS courses were developed by teams of 2-4 faculty from various disciplines, many from the civil and mechanical programs. Whereas students did not learn mechanics concepts as applied to engineering systems until their sophomore year in the traditional curriculum, students in the new curriculum are introduced to basic mechanics principles starting first semester freshman year with EAS107P Introduction to Engineering - Project-Based. Second semester freshman year all students take an engineering analysis course, EAS112 Methods of Engineering Analysis, which uses computer tools such as spreadsheets to solve a variety of problems.

First semester sophomore year students take PH150 concurrently with two engineering courses; namely, EAS211 Introduction to Modeling of Engineering Systems and EAS213 Materials in Engineering Systems. The rationale for moving PH150 from second semester freshman year to first semester sophomore year was to simultaneously integrate topics discussed in Physics with engineering applications in EAS211. Second semester sophomore year both CE and ME students take EAS222 Fundamentals of Mechanics and Materials, which draws on students' understanding of force balances and material properties from EAS211 and EAS213, respectively.

Junior level courses in both the civil and mechanical engineering programs are still discipline specific in the new curriculum. However, due to the content of sophomore year courses, restructuring of the curriculum for the ME students was warranted. First semester junior year all CE students take CE312 Structural Analysis. It is expected that students who have taken the EAS sequence of courses are prepared to take CE312 in an equivalent manner to those who would have taken the traditional CE205 course. Thus, no changes in CE312 were made in the new curriculum. However, the ME program restructured the sequence of courses taken first semester junior year. ME307 Solids Mechanics was replaced by ME300 Rigid Body Dynamics and ME308 Applied Elasticity (4 credits). An explanation of the rationale for making these changes will be discussed in the next section that describes how mechanics topics are threaded throughout the EAS sequence of courses.

\section{Threading of Mechanics Topics in EAS Courses}

The overall intent of the mechanics thread in the multidisciplinary curriculum is to develop sufficient skills and capabilities so a student may enter disciplinary courses in the junior year with similar capabilities and skills that the traditional student would have. While there is no expectation of similar depth to a traditional program, the improved problem solving and multidisciplinary perspective should provide the student with an equal capacity for success. The addition of mechanics topics beginning in the freshman year and culminating in the disciplinary courses in the first semester junior year should produce a more competent and capable engineering student, with characteristics closer to the engineer of 2020.

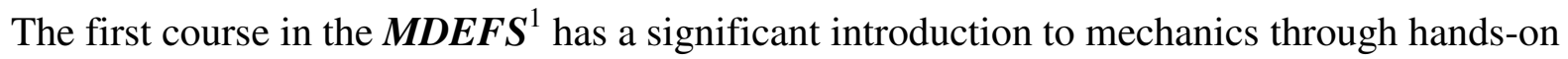
projects and traditional textbook problems. The course, EAS107P Introduction to Engineering, Project-Based, has a bridge design project as the second major project of five ${ }^{3}$. This bridge 
project attempts to build an intuitive understanding of the mechanics of truss design while providing an enjoyable and competitive exercise in student teamwork and management. The project objective is to design the least expensive bridge that satisfies the design requirements established by a fictional client. An assessment of the requirements uses a Kepner-Tregeo style decision matrix, similar to the decision matrix in the required text "Foundations of Engineering" by Holtzapple $\&$ Reece ${ }^{4}$. To design the bridge truss, a number of elements build the conceptual framework.

First, the students intuitively build a 6-inch water tower out of spaghetti with a cardboard base to support a 500ml beaker. The tower and beaker are weighed and the beaker filled with water until the structure collapses. The winner is the student group with the highest load to weight ratio, identifying the most efficient structure. At this point, after the excitement of the event is over, the idea of a two-force member and trusses are introduced through force balance on a simply supported three-member truss. After calculating the reactions and loads for a variety of geometries, applied problems are introduced to relate the simplistic model with the real world. A crane, holding a load on a cable, with an additional support cable tied to the frame of the crane is reviewed in detailed, including an introduction to calculating stress.

The next element has the students constructing five different roof trusses and applying simply supported boundary conditions. Students first use the John Hopkins truss design program ${ }^{5}$ to generate forces for each of the members, then are assessed on their ability to explain how the truss redistributes a simulated snow load. The major element of the project is the design of a 44meter truss bridge using the West Point Bridge Design program ${ }^{6}$ and recording the optimization process through the three variations in materials and hollow or solid cross-sections. A fully optimized bridge based on cost and the decision matrix is developed by a team of students while working through basic $2 \mathrm{D}$ force balance problems from the text.

The fall 2006 semester was the first to introduce quantitative force balance and stress calculation for design. This mixture of quantitative problem solving along with the qualitative understanding from the projects will continue in the future as we refine the course and improve student retention of analytic skills. On the final exam given almost two months after the end of the mechanics portion of the course, mechanics questions were given to assess retention of concepts. Fifty percent of the students were able to solve $2 / 3$ of the mechanics problems correctly. A specific measure for performance is still under discussion but the expectation of the faculty teaching the freshman course was $70-80 \%$ of the students should be able to solve $2 / 3$ of the mechanics problems. The addition of increased analytic skills is in response to the perceived capability of our entering freshman. A further review of the students and the degree to which the analytic content is emphasized will be ongoing.

The second semester freshman course, EAS112 Methods of Engineering Analysis, extends the mechanics thread further with an emphasis on capability to compute solutions to a reasonably complex engineering problem given the governing equations. Skills at setting up problems on a spreadsheet and programming in visual basic are combined to provide a platform for generalized problem solving applied to thermo-fluids, mechanics, material balances and electrical circuits typically encountered in sophomore level courses. The mechanics problems included in the course emphasize: 2D force resolution, reaction calculations, method of joints for simple trusses, 
solving kinematics of particles in 2D using numerical integration to find velocity and displacement and iteration methods to optimize mechanics problems for cost and weight. While the course focus is the development of techniques and tools for computerized problem solving, the mechanics topics are integrated in class and homework problems or projects and provide a second pass of the spiral curriculum in these topics. The ease of computing alternative solutions and point optimization using the features of Excel and VBA allows for a design oriented solution to many of the problems encountered in the course. For example, the structure cost is optimized in the bridge truss project and hydrogen flow rate is maximized in fuel reformer project.

To measure the performance, retention and preparation for the next sequence of courses, typical mechanics problems were given on the EAS112 spring 2006 final exam. After summarizing and reviewing the student performance, the combined scores for multiple sections resulted in exactly $66.7 \%$ of the students able to solve $2 / 3$ of the mechanics problems correctly. Again, while there is not an established outcome measure for performance in this area, the expectation was a bit higher. This level of performance will be monitored as the sophomore students who were tested progress to their last semester of the spiral curriculum and final course in the mechanics thread.

One of two engineering courses taken first semester sophomore year, EAS211 Introduction to Modeling of Engineering Systems, focuses on the development of students' problem solving skills, while introducing them to fundamental principles from various engineering fields that will be further developed in some areas in subsequent courses. The application of conservation principles for solving engineering problems is a unifying theme throughout the course. The intent of the course is not to focus as much on the mechanics of how to solve certain problems, but rather on students' conceptual understanding of the underlying principles needed to solve these problems.

In the area of mechanics, students solve problems based on conservation of linear and angular momentum for both open and closed systems, under transient and steady-state conditions. Students gain experience more in the solution of closed systems under steady state conditions; however, open system problems include determining the height that a bottle rocket would reach by varying the bottle opening, and mass of water in the bottle. Students analyze the behavior of trusses under concentrated and distributed loads, including the computation of equivalent forces and where they act, and use the Methods of Joints to determine the compressive and tensile forces in truss members.

EAS213 Materials in Engineering Systems is a unique course that is in part based on the work of Texas A\&M as part of the Foundation Coalition ${ }^{7}$. EAS213 focuses on the physical behavior of gases, liquids and solids and acts to compliment EAS211 Introduction to Modeling of Engineering Systems. The properties of solids are covered with an emphasis on understanding the behavior of materials under structural and thermal loadings. The course begins with coverage of the behavior of gases and liquids, then progresses to solid materials starting with basic crystal structure and phase diagrams, which are very similar to gas-liquid phase diagrams. The influence of the crystal structure on mechanical properties is covered; as is the typical cold working, strain hardening and annealing behavior typical of a traditional course in material science. This course then emphasizes the common types of mechanical behavior of all solid materials: Young's modulus, yield and tensile strength, elongation and Poisson ratio, fracture 
toughness, fatigue strength, and creep behavior. Each of the classes of materials; namely, ferrous alloys, non ferrous alloys, polymers, ceramics and composites, are reviewed for their general mechanical behavior and technique for computing simple loading situations covered for each type of mechanical behavior. Experimental testing and demonstrations provide students with a strong physical reference for properties and numerous homework problems and quizzes reinforce these concepts. Preliminary results from the final exams from the multiple sections taught in the fall 2006 semester indicate an overall average performance of $70 \%$ able to correctly solve problems when tested on: cold working and annealing, Poisson ratio, shear modulus and twist angle, tensile behavior, elongation under loading and true stress-strain. When tested on fracture, fatigue and creep failure, the average student performance was $72 \%$ correct. While these performance measures are very preliminary, further study of the long-term performance of the students and retained content will continue with this cohort.

EAS222 focuses on the fundamentals of mechanics and materials. Topics discussed in this course are similar to those taught in the statics and strength of materials course CE205.

However, the major difference between these two courses is the reduced amount of statics included in EAS222 and the addition of particle dynamics. Statics topics such as particle and rigid body equilibrium; the analysis of trusses, beams and frames; section properties (centroids and moment of inertia) and stress and strain relationships are all covered in EAS222 in a review fashion rather than as strictly new material. This is based on the assumption that students have been exposed to these topics in the previous EAS courses, along with physics.

Most of the topics related to mechanics of materials in EAS222 are the same as those taught in CE205. The exception to this is the material properties section, that is, force-stress-straindeformation relationships. These topics are assumed to be covered in the EAS213 course. The dynamics portion of EAS222 only covers particle dynamics, both kinematics and kinetics. Again assumptions are made that students have seen some of the basics in previous courses, but less of the previous work is relied on here than in the statics portion of the course. This course was offered for the first time during the spring 2006 semester.

The first few courses in the mechanical engineering sequence were changed from the traditional courses to take advantage of the expected improvement in student breadth and capability in the new curriculum. The new sequence at the disciplinary junior level begins with two entirely new courses ME300 Rigid Body Dynamics for 3-credits and ME308 Applied Elasticity for 4-credits. The first course continues the topics of dynamics covered in EAS222 but with a focus on rigid bodies rather than particles and includes some vibration content, which is often included at the end of dynamics texts. The other course, applied elasticity, is very similar to the original ME307, including all of the same content of ME307 but adds additional topics in elasticity presuming a more advanced student entering at the junior level.

\section{Assessment}

The changes made in the curriculum along with restructuring of courses are expected to result in the following improvements:

- Students develop a multidisciplinary view of mechanics; 
- Better problem solving ability in mechanics and applying mechanics concepts to other areas;

- More confident students who perform better at the Junior level;

- Graduates who can work in the mechanics areas of $\mathrm{CE}$ and ME with a greater appreciation for the impact and needs of other disciplines; e.g. Chemical Engineering, Electrical Engineering, etc.

Throughout the development of the curriculum, numerous outcome measures were considered for assessing student performance. Among these is the general portion of the NCEES

Fundamentals of Engineering exam, which offers a nationally accepted benchmark for student performance. The Foundation Coalition "concept inventories"7 provide key measures of student comprehension in numerous areas of mechanics, including dynamics, materials and strength of materials. In the short term, our early benchmark has had to be the entry of students into the first disciplinary courses at the beginning of the $3^{\text {rd }}$ year. As the implementation of the curriculum continues broader benchmarks, like the ones identified above, will need to be adopted.

Students who entered the University of New Haven in fall 2004 were the first cohort of students to take the MDEFS sequence of courses. During the fall 2006 semester these students starting taking junior level mechanics courses that included CE312 for the civil engineering students and ME300 for the mechanical engineering students. Thus, assessment of the some of the expected improvements listed above is limited to students' performance in junior level courses at this point in time. The section of CE312 was particularly small during the fall 2006 semester; therefore, only a preliminary assessment of students' performance in ME300 will be addressed.

ME300 was offered for the first time during the fall 2006 semester, replacing ME204 previously taken during second semester sophomore year as part of the traditional curriculum. The student profile for the course consisted of a group of mostly CE and ME students who had taken the EAS sequence of courses and those who had followed the traditional curriculum (non-EAS) but were allowed to take the new course as an alternative. Out of the 15 students in the class, $7 \mathrm{ME}$ students took EAS courses, 6 students took non-EAS courses including 3 CE students, and 2 students had other majors (not included in the analysis).

Student performance was measured by determining the average final grade for the two groups of students (EAS vs. non-EAS), and comparing these averaged scores. Summarized in Figure 2 are the average final grades for the EAS and non-EAS student cohorts, along with normalized grades. The EAS student cohort had an average final grade of 3.01 versus 2.62 for the non-EAS students (13\% difference). To account for differences in students' academic abilities, individual grades were normalized first by their cumulative grade point average (GPA) prior to taking the course, and then by the fall 2006 term GPA. Regardless of the GPA used to normalize the data, the trend was similar. Based on using a cumulative GPA, the normalized average grade for the EAS cohort was 1.03 compared to 0.92 for the non-EAS students and 1.06 (EAS) versus 0.95 (non-EAS) using the term GPA to normalize the grades. The relatively low number of students in this class does not allow us at this time to determine whether the approximately $11 \%$ increase in the EAS cohort final grades is statistically significant or not. However, this preliminary assessment appears to suggest that the EAS cohort of students, on average, performed at least as well as the students who took the more traditional curriculum. 


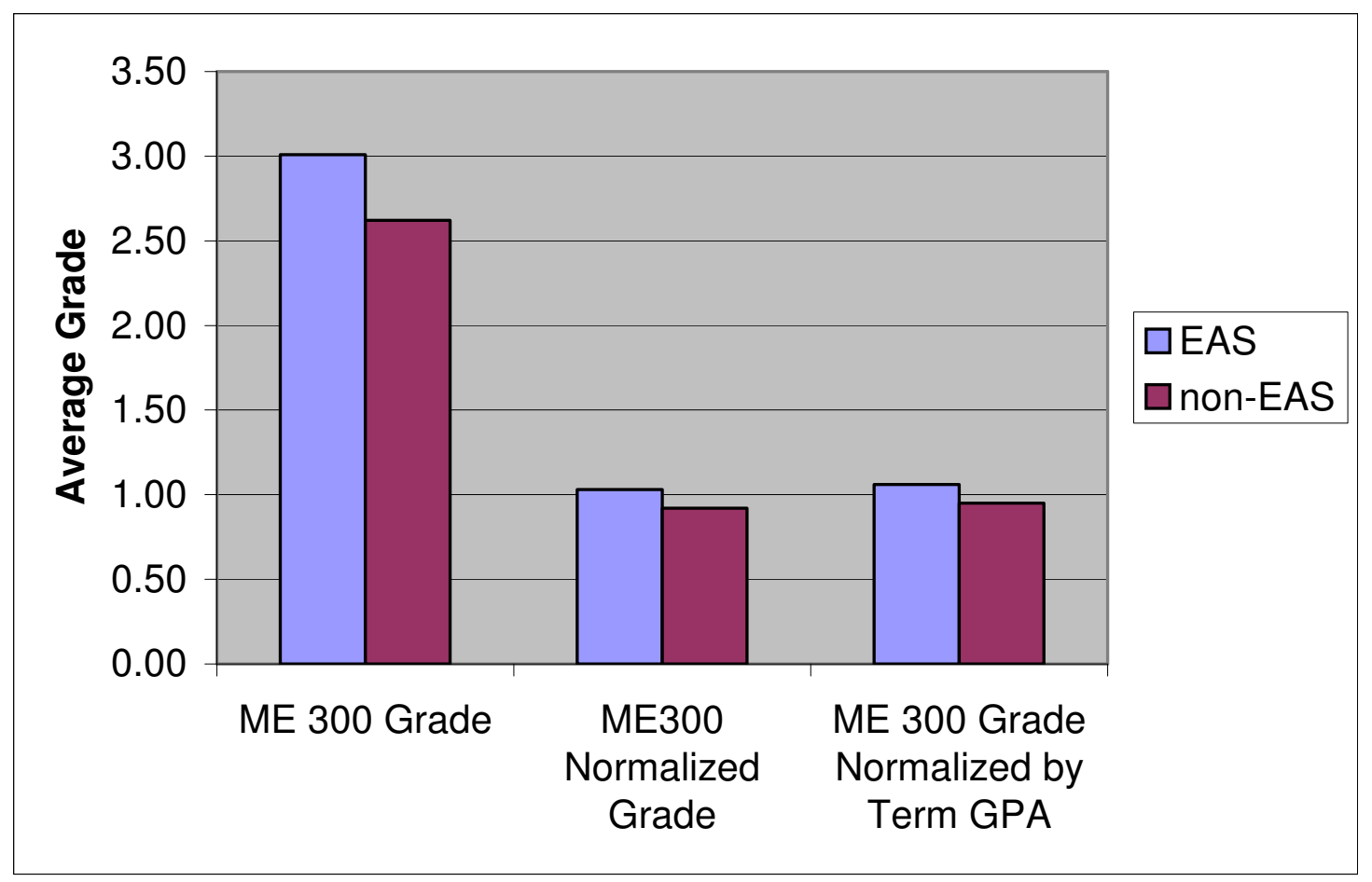

Figure 2. Student Performance in Junior Level Mechanics Course

In the first disciplinary courses, faculty play an important role in assessing the adequate preparation of students and provide our initial assessment of the successful preparation of the students for further courses in mechanics. Given the broad exposure that students receive in the new curriculum to engineering and applied science topics as compared to the traditional, the student preparation for success in disciplinary courses must be considered a minimum outcome of the curriculum, which at this point is indicated by the performance of the students in ME300.

The new curriculum is aimed at a broader understanding of engineering topics, linking the similarity in other engineering areas with mechanics and leveraging that broader understanding to improve conceptual and analytic skills. The faculty teaching the last mechanics section of the EAS curriculum (EAS222) and the faculty teaching the first disciplinary junior level course (ME300) were surveyed for their rating of student performance. The faculty rating of EAS and non-EAS student performance in key areas of mechanics in ME300 was 3.6/5 for the non-EAS and 4.1/5 for the EAS students. The rating of the problem solving skills and ability to learn new concepts in mechanics was for EAS students only in both EAS222 and ME300. Figure 3 shows the average rating of the EAS students for the following questions:

Q1: Rate the student's ability to formulate their own equations for problem solving.

Q2: Rate the student's ability to learn and apply new mechanics concepts.

The EAS students show an apparent increase in these key developmental areas. The students in EAS222, at the end of the sophomore year, have a rating of 3.6-3.8 which on the questionnaire equates to somewhere between neutral (3) and agree (4) on questions $1 \& 2$. The students in 
ME300, at the end of the first semester junior year, have a rating of 4.3, which corresponds on the questionnaire to a higher rating than agree (4) but not quite strongly agree (5). The small sample of students is insufficient to draw any conclusions at this time but there is clearly an upward trend in student performance.

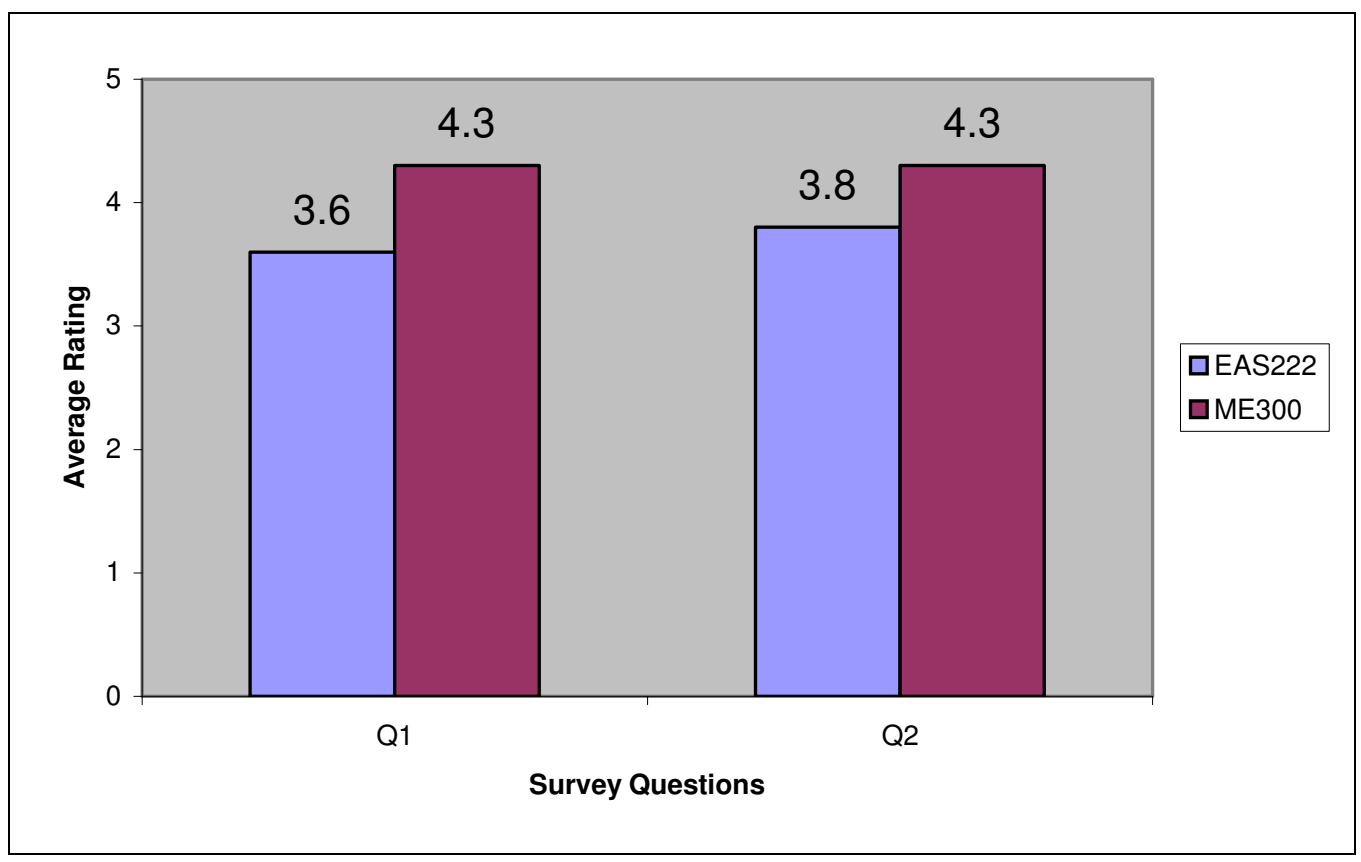

Figure 3. Faculty Perception of Student Performance in Mechanics Courses

\section{Conclusions}

The complete sequence of courses in the MDEFS is now being offered during the 2006-07 academic year. The fall 2006 semester marked the first time that students in the new curriculum took discipline specific junior level mechanics courses. Assessment of students' performance in these classes is inconclusive at this time due to limited data but the data does indicate an improved trend. These preliminary indicators suggest that EAS students are as prepared as their peers who took traditional courses. Performance of students in the junior level mechanics courses will continue to be monitored and collected for assessment.

\section{References}

1. Collura, M.A., B. Aliane, S. Daniels, and J. Nocito-Gobel, "Development of a Multi-Disciplinary Engineering Foundation Spiral", Proceedings, 2004 American Society for Engineering Education Annual Conference and Exposition, Salt Lake City, Utah, June 20 - 23, June 2004.

2. Foundation Coalition Website: http://www.foundationcoalition.org/home/sophomore/index.html 
3. Nocito-Gobel, J., S. Daniels, M. Collura, and B. Aliane, "Project-Based Introduction to Engineering - a University Core Course", Proceedings, 2004 American Society for Engineering Education Annual Conference and Exposition, Salt Lake City, Utah, June 20 - 23, 2004.

4. Holtzapple, M.T. and W.D. Reece, Foundations of Engineering, $2^{\text {nd }}$ ed., McGraw-Hill Higher Education, 2003.

5. John Hopkins Virtual Laboratory, Bridge Designer, http://www.jhu.edu/ virtlab/virtlab.html.

6. Col. S. Ressler, U.S. Military Academy, West Point Bridge Designer, http://bridgecontest.usma.edu

7. Foundation Coalition Website:

http://www.foundationcoalition.org/home/keycomponents/concept/introduction.html 